\title{
ANATOMICAL CHARACTERISTICS OF THE TEMPOROFACIAL NERVE BRANCH WITHIN THE PAROTID GLAND IN VIETNAMESE ADULTS
}

\author{
Pham Ngoc Minh*
}

\section{ABSTRACT}

Objectives: Describe anatomical characteristics of the temporal branch of the facial nerve within the parotid gland in Vietnamese adults. Study population: The study was conducted in 12 hemifaces (right: 7; left: 5) of Vietnamese adult cadavers ( 5 cadavers with both hemifaces and 2 cadavers with only hemiface). Gender: 4 male $(57.1 \%)$ and 3 female $(42.9 \%)$. The average age was $73.0 \pm 13.39$ years (52-88 years). Method: Descriptive crosssectional with analysis. Result and Conclusion: Most of the temporofacial trunks were located within the parotid gland $(81.8 \%) ; 18.2 \%$ were located behind the parotid gland. The length of the facial nerve within the parotid gland was 8.88 $\pm 3.55 \mathrm{~mm}(4.62-16.96 \mathrm{~mm})$. The distance from the division point of the temporofacial trunk into the temporofrontal branch and the orbital nerve branch to the line (d) [crossing through the lateral canthus (A) and the point that root of the helix intersecting with the face] and (d2) [crossing the lateral canthus and the upper point of the tragus, just above the upper edge of external auditory canal] was $36.06 \pm 7.50 \mathrm{~mm}(19.26-45.34 \mathrm{~mm})$ và $21.94 \pm 6.28 \mathrm{~mm}(11.52-37.20 \mathrm{~mm})$.

\section{INTRODUCTION}

The temporal branches originate from the temporofacial trunk then travel from down upwards and devide into its 3 main branches: temporal, zygomatic and buccal. Most of these branches $(83 \%)$ can merge to form a

\footnotetext{
* 108 Military Central Hospital

Responsible person: Pham Ngoc Minh Email: minhphamngoc81@yahoo.com Date of receipt: 15/6/2021

Date of scientific judgment: 25/7/2021 Reviewed date: 18/8/2021
}

nerve plexus [1] [2] [3]. Normally, there may be 1,2 or 3 branches which divide further within the gland. These branches cross the zygomatic arch to the temporal region and innervate the intrinsic muscles of the ear, anterior auricular muscle, superior auricular muscle, the occipital belly of the occipitofrontalis muscle, corrugator muscle and the orbicularis muscle. The temporal branches unite with the auriculotemporal branches of the mandibular nerves (V3); or with the zygomaticotemporal branches of the maxillary nerves (V2). The branches which provide innervation to the orbicularis muscle, corrugtor muscle, the frontal belly of the occipitofrontalis muscle merge with supraorbital branches and the lacrimal nerve branches of the ophthalmic nerve [4][5][6][7].

The temporofacial branches within the parotid gland are vulnerable in surgery. Thus, we conducted this study: "Anatomical characteristics of the temporofacial nerve branch within the parotid gland in Vietnamese adults" with the aim of avoiding injuries to the branch in maxcillofacial surgery.

\section{METHOD}

\section{Study population and method}

12 hemifaces (right: 7; left: 5) of Vietnamese adult cadavers (5 cadavers with both hemifaces and 2 cadavers with only hemiface) were dissected. Gender: 4 male $(57.1 \%)$ and 3 female (42.9\%). The average age was $73.0 \pm 13.39$ years $(52-88$ years $)$. 
These cadavers were stored by formolin at Department of Anatomy, Ho Chi Minh City University of Medicine and Pharmacy.

\section{Inclusion criteria:}

- The cadavers were eligible with convenience sampling method, which were used as teaching materials for students at the Department of Anatomy of Ho Chi Minh City University of Medicine and Pharmacy.

- No surgical history in the face

- The cadavers were stored in less than 2 years.

\section{Exclusion criteria:}

- Congenital or pathological abnormalities, any facial surgery that can alter the facial structure anatomy.

- Cadavers were not in standard preservation or had poor quality that can affect the study results.

- Cadavers with unknown year of birth.

- Cadavers who were foreigner.

\subsection{Method}

* Study design: descriptive cross-sectional with analysis
* Materials:

- Data collection form

- Nikon D90 camera, Macro lens

- Dissection equipment kit with scalpel, dissection scissors, Kelly forceps, Allis forceps, Adson forceps and tissue forceps.

- Measuring tool kit with caliper, obstuse ruler, angle ruler.

* The anatomical landmarks in the study (Figure 1) were designed based on the references of similar anatomical studies and the specific purpose of this study:

- Point A: lateral canthus

- Point B: the intersecting point of the root of the helix with the face

- Point C: point in the tragus, just above the upper edge of external ear canal (tragion)

- Point O: the division point of the temporofacial trunks into the temporofacial branch and the orbital branch.

- Point M: where the temporal branch exits the upper edge of the parotid gland. In case there are 2-3 temporal branches, they will be designated as M1, M2, M3.

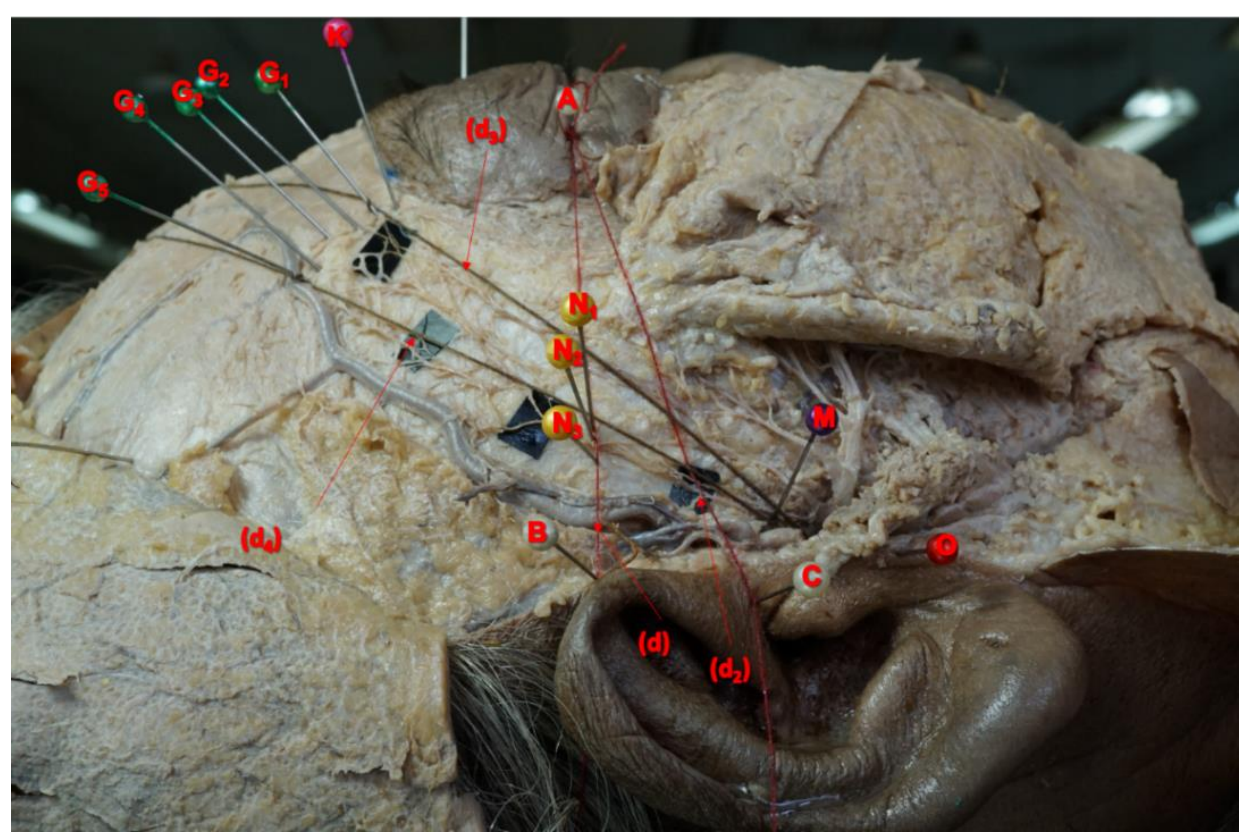

Figure 1: Anatomical landmarks and parameters in the study 
* Parameters in the study

- The superficially-oriented lines of the frontal branches of the facial nerve:

$+(\mathrm{d})$ : line crossing point A and B

$+(\mathrm{d} 2)$ : line crossing point $\mathrm{A}$ and $\mathrm{C}$

- OM: length of the temporal branch within the parotid gland.

- to: depth of the OM nerve measured at the midpoint.
- r0: width of the OM nerve measured at the midpoint,

- dO: distance from point $\mathrm{O}$ to the line (d).

- $\mathrm{d} 2 \mathrm{O}$ : distance from point $\mathrm{O}$ to the line (d2).

Variables were in millimeters $(\mathrm{mm})$.

* Data analysis: using SPSS 22.0 with $\chi^{2}$ test, t-test (with $\mathrm{p}<0.05$ ). Data was rounded to 2 decimal places.

\section{RESULTS}

Table 1. The relationship between the temporofacial trunk and the parotid gland

\begin{tabular}{|l|c|c|c|c|c|c|}
\hline \multirow{2}{*}{ Parameters } & \multicolumn{2}{c|}{$\begin{array}{c}\text { Right } \\
(\mathbf{n = 7 )}\end{array}$} & \multicolumn{2}{c|}{$\begin{array}{c}\text { Left } \\
(\mathbf{n = 4 )}\end{array}$} & \multicolumn{2}{c|}{$\begin{array}{c}\text { overall } \\
(\mathbf{n = 1 1 )}\end{array}$} \\
\cline { 2 - 7 } & No & \% & No & \% & No & \% \\
\hline Within the parotid gland & 6 & 85.7 & 3 & 75.0 & 9 & 81.8 \\
\hline Behind the parotid gland & 1 & 14.3 & 1 & 25.0 & 2 & 18.2 \\
\hline
\end{tabular}

Table 1 shows that most of the temporofacial trunks were within the parotid gland $(81.8 \%) ; 18.2 \%$ were located behind the parotid gland.

Table 2. Dimensions of the temporal branches within the parotid gland

\begin{tabular}{|c|c|c|c|}
\hline Dimensions & $\begin{array}{l}\text { Right } \\
(n=7)\end{array}$ & $\begin{array}{c}\text { left } \\
(n=4)\end{array}$ & $\begin{array}{c}\text { overall } \\
(n=11)\end{array}$ \\
\hline \multirow{2}{*}{$\begin{array}{l}\text { Length (OM) (mm) } \\
(\bar{X} \pm S D)\end{array}$} & $7.74 \pm 2.59$ & $10.87 \pm 4.51$ & \multirow{2}{*}{$\begin{array}{r}8.88 \pm 3.55 \\
(4.62-16.96) \\
\end{array}$} \\
\hline & \multicolumn{2}{|c|}{$p>0.05$} & \\
\hline \multirow{2}{*}{$\begin{array}{l}\text { Width (ro)(mm) } \\
(\bar{X} \pm S D)\end{array}$} & $08.5 \pm 0.16$ & $0.84 \pm 0.24$ & \multirow{2}{*}{$\begin{array}{l}0.85 \pm 0.18 \\
(0.56-1.12) \\
\end{array}$} \\
\hline & \multicolumn{2}{|c|}{$p>0.05$} & \\
\hline \multirow{2}{*}{$\begin{array}{l}\text { Depth (to) (mm) } \\
(\bar{X} \pm S D)\end{array}$} & $0.19 \pm 0.05$ & $0.19 \pm 0.04$ & \multirow{2}{*}{$\begin{array}{c}0.19-0.04 \\
(0.12-0.28) \\
\end{array}$} \\
\hline & \multicolumn{2}{|c|}{$p>0.05$} & \\
\hline
\end{tabular}

Table 2 illustrates the length of the facial nerve within the parotid gland was $8.88 \pm 3.55$ $\mathrm{mm}(4.62-16.96 \mathrm{~mm})$; the width at the midpoint was $0.19-0.04 \mathrm{~mm}(0.12-0.28 \mathrm{~mm})$, there was no difference between right and left side ( $p>0.05)$.

Table 3. Distance from the division point of the temporofacial trunk into the temporofrontal branch and the orbital branch to the line (d) and (d2)

\begin{tabular}{|c|c|c|c|}
\hline Parameters & $\begin{array}{l}\text { Right } \\
(n=7)\end{array}$ & $\begin{array}{l}\text { left } \\
(n=5)\end{array}$ & $\begin{array}{l}\text { Overall } \\
(n=12)\end{array}$ \\
\hline \multirow{2}{*}{$\begin{array}{l}\text { Distance (dO) (mm) } \\
\left(\bar{X}_{ \pm} \mathrm{SD}\right)\end{array}$} & $36.77 \pm 4.65$ & $35.06 \pm 10.97$ & \multirow{2}{*}{$\begin{array}{c}36.06 \pm 7.50 \\
(19.26-45.34)\end{array}$} \\
\hline & \multicolumn{2}{|c|}{$p>0.05$} & \\
\hline \multirow{2}{*}{$\begin{array}{l}\text { Distance (d2O) (mm) } \\
(\bar{X} \pm \text { SD) }\end{array}$} & $20.52 \pm 3.39$ & $23.93 \pm 9.11$ & \multirow{2}{*}{$\begin{array}{c}21.94 \pm 6.28 \\
(11.52-37.20)\end{array}$} \\
\hline & \multicolumn{2}{|c|}{$p>0.05$} & \\
\hline
\end{tabular}


Table 3 shows that the distance from the division point of the temporofacial trunk into the temporofrontal branch and the orbital branch to the line (d) [crossing the lateral canthus and the root of the helix] was [36.06 $\pm 7.50 \mathrm{~mm}(19.26-45.34 \mathrm{~mm})$ and to the line (d2) [crossing the lateral canthus and the tragus, just above the external auditory canal] was $21.94 \pm 6.28 \mathrm{~mm}(11.52-37.20 \mathrm{~mm})$, there was no difference between right and left side ( $p>0.05)$.

Table 4. Distance from the facial nerve above the zygomatic arch to the anatomical landmarks in different studies

\begin{tabular}{|c|c|c|c|}
\hline \multicolumn{2}{|r|}{ Parameters (mm) } & Right & Left \\
\hline \multirow{5}{*}{$\begin{array}{l}\text { Farahvash M. R. et } \\
\text { al., } 2013 \\
\text { (Right: } n=21 \text {; } \\
\text { Left: } n=21 \text { ) }\end{array}$} & $\begin{array}{l}\text { Distance from the facial nerve above the zygomatic } \\
\text { arch to the stylomastoid foramen }\end{array}$ & $\begin{array}{r}11.81 \\
\pm 2.01 \\
\end{array}$ & $\begin{array}{r}11.62 \\
\pm 1.93\end{array}$ \\
\hline & $\begin{array}{l}\text { Distance from the upper edge of the tragus to the } \\
\text { lateral canthus }\end{array}$ & $\begin{array}{l}72.76 \\
\pm 7.30\end{array}$ & $\begin{array}{l}73.24 \\
\pm 6.97\end{array}$ \\
\hline & $\begin{array}{l}\text { Distance from the } 1^{\text {st }} \text { temporofrotal branch to the } \\
\text { upper edge of the tragus }\end{array}$ & $\begin{array}{l}20.62 \\
\pm 3.84\end{array}$ & $\begin{array}{l}21.33 \\
\pm 3.10\end{array}$ \\
\hline & $\begin{array}{l}\text { Distance from the } 2^{\text {nd }} \text { temporofrontal branch to the } \\
\text { upper edge of the tragus }\end{array}$ & $\begin{array}{r}28.05 \\
\pm 5.10\end{array}$ & $\begin{array}{c}27.6 \\
\pm 3.84 \\
\end{array}$ \\
\hline & $\begin{array}{l}\text { Distance from the } 3^{\text {rd }} \text { temporofrontal branch to the } \\
\text { upper edge of the tragus }\end{array}$ & $\begin{array}{l}35.00 \\
\pm 4.98\end{array}$ & $\begin{array}{l}35.67 \\
\pm 3.55\end{array}$ \\
\hline \multirow{2}{*}{$\begin{array}{l}\text { Our study (2019) } \\
\text { (Right: } \mathrm{n}=7 \\
\text { Left: } \mathrm{n}=5 \text { ) }\end{array}$} & $\begin{array}{l}\text { Distance from division point of the temporofrontal } \\
\text { branch to the line (d) }\end{array}$ & $\begin{array}{l}36.77 \\
\pm 4.65\end{array}$ & $\begin{array}{r}35.06 \\
\pm 10.97\end{array}$ \\
\hline & $\begin{array}{l}\text { Distance from division point of the temporofrontal } \\
\text { branch to the line }(\mathrm{d} 2)\end{array}$ & $\begin{array}{r}20.52 \\
\pm 3.39\end{array}$ & $\begin{array}{l}23.93 \\
\pm 9.11\end{array}$ \\
\hline
\end{tabular}

(d) [line crossing the lateral canthus and immediately entered the parotid salivary the root of the helix]

(d2) [line crossing the lateral canthus and the tragus, just above the outer ear canal]

Table 4 illustrates that the distance from branches of the facial nerve to the anatomical landmarks were similar but the identification method of these landmarks was different among studies depend on the study's purpose.

\section{DISCUSSION}

4.1. The relationship between the temporal branch of the facial nerve and the parotid gland

The division of the temporal branch originated about $2 \mathrm{~cm}$ above the tragus [2], [3], [5]. According to Nguyen Van Thanh et al. (1992): $94 \%$ of the nerve VII exited the skull at the stylomastoid foramen and gland, $6 \%$ travel about $5 \mathrm{~mm}$ before reaching the gland [1]. This segment of the nerve was located about $1 \mathrm{~cm}$ to more than $2 \mathrm{~cm}$ under the skin.

In our study, the majority of the temporofacial branches were located within the parotid gland $(81.8 \%) ; 18.2 \%$ of cases were located behind the gland (Figure 2). These results were similar to the findings of Nguyen Van Thanh et al (1991) [1] in 43 hemifacies (21 right, 22 left) of 17 cadavers and 5 fresh corpses, aged from 40 to 65 . In their study, the facial nerve from its origin turned upward to the forehead. 98\% (42/43) of the temporofacial nerves left the gland in the superior border, the remaining $2 \%$ of cases, the nerve ran superficially beyond the gland, just in front of the external auditory canal. 


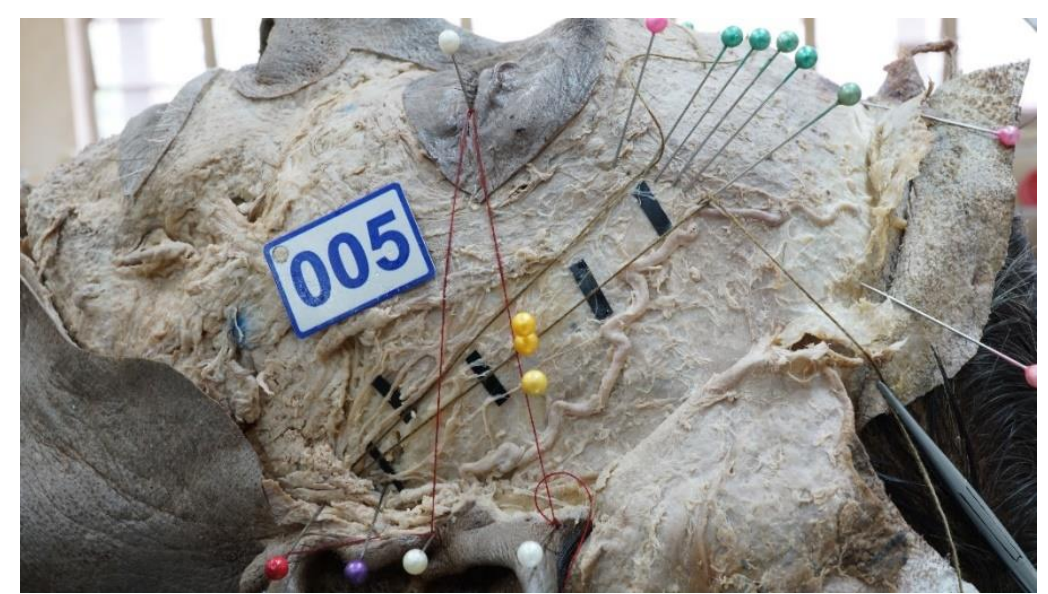

Figure 2. The temporal branch of the facial nerve within the parotid gland (left ear)

(Source: Specimen code 10356)

4.2. Dimensions and localization of the temporal branch within the parotid gland

In our study, the average length of the temporal branch within the parotid gland was $8.88 \pm 3.55 \mathrm{~mm}(4.62-16.96 \mathrm{~mm})$; the width and depth of the temporal branch within the parotid gland measured at the midpoint were $0.85 \pm 0.18 \mathrm{~mm}(0.56-1.12 \mathrm{~mm})$ and 0.19 $0.04 \mathrm{~mm}(0.12-0,28 \mathrm{~mm})$, there is no difference between right and left side ( $>>0.05)$, (table 2). The length of the temporal branch within the parotid gland in our study $(8.88 \pm 3.55 \mathrm{~mm})$ was similar to the study of Nguyen Van Thanh et al (1991) [1] in Vietnamese cadavers: the nerve segment within or posterior to the parotid gland was about $8 \mathrm{~mm}$ long.

The localization of the temporal branch within the parotid gland showed the distance from the point that the temporal branch of the facial nerve divided into the temporofrontal branch and the orbital branch to the line (d) [line crossing through the lateral canthus and the intersecting point of root of the helix and the face] was $36.06 \pm 7.50 \mathrm{~mm}$ (19.26- 45.34 $\mathrm{mm})$ and to the line (d2) [line crossing through the lateral canthus and the tragus, just above the upper edge of the external auditory canal] was $21.94 \pm 6.28 \mathrm{~mm}$ (11.52$37.20 \mathrm{~mm}$ ), (table 3$)$.
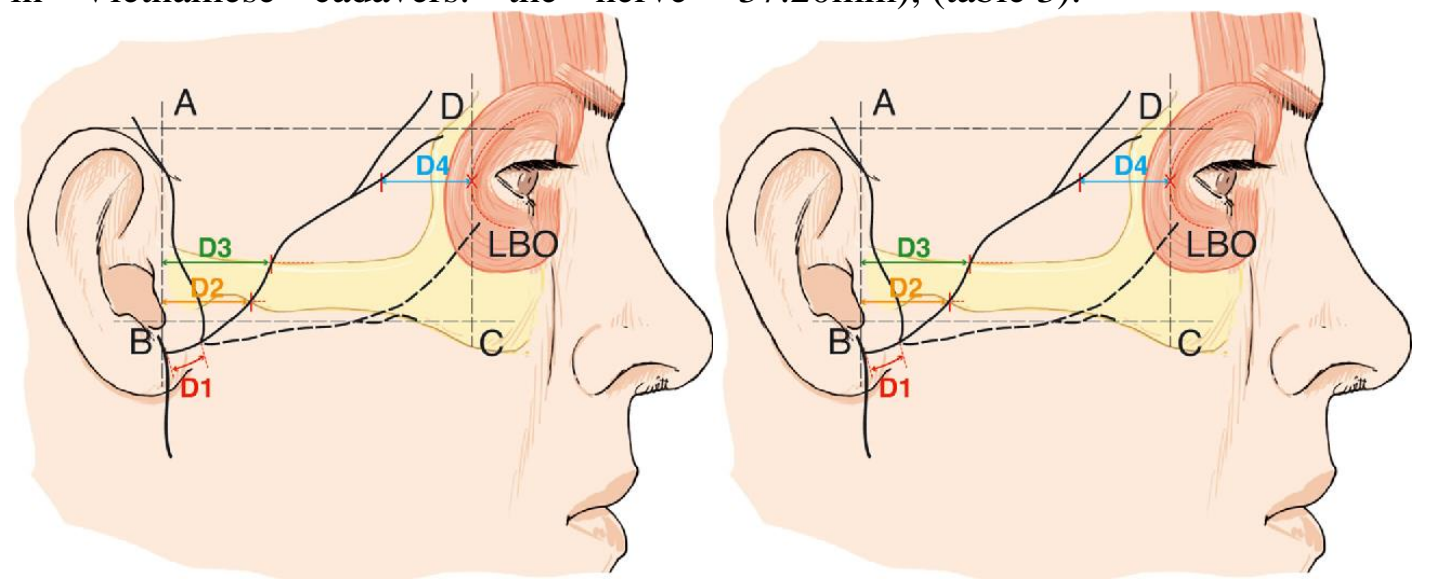

Figure 3. The vulnerable area of the temporal nerves in surgery

(Source: de Bonnecaze G. et al., 2015) 
Our results were similar to the findings of Farahvash M. R. et al. (2013) [7] in an analysis of 42 hemifacial dissections from 21 fresh Persian (Iranian) cadavers. The distance from the nearest temporal nerve branch above the zygomatic arch to the tragus was $20.62 \pm 3.84 \mathrm{~mm}$ (on the right) and $21.33 \pm$ $3.10 \mathrm{~mm}$ (on the left), (table 4). De Bonnecaze G. et al. (2015) when dissecting 12 fresh corpses (24 facial nerves) identified the vulnerable zone of the temporal branch below the zygomatic arch (> 85\%) was $22.6 \mathrm{~mm}$ to $26.06 \mathrm{~mm}$ anterior to the tragus and above the zygomatic arch (>85\%) was 27.46 to 30.43 $\mathrm{mm}$ anterior to the tragus (Figure 3) [6].

De Bonnecaze G. et al., 2015 [6] states that 'there exists no real area of anatomical safety in the temporal region'. However, identifying areas of relative safety would be of great assistance to the surgeons or morphologists to approach pathologies.

\section{CONCLUSION}

The study was conducted in 12 hemifaces (right: 7; left: 5) of Vietnamese adult cadavers ( 5 cadavers with both hemifaces and 2 cadavers with only hemiface). Gender: 4 male $(57.1 \%)$ and 3 female $(42.9 \%)$. The average age was $73.0 \pm 13.39$ years $(52-88$ years).

- Majority of the temporofacial trunks were within the parotid gland $(81.8 \%)$; $18.2 \%$ were located behind the parotid gland. The length of the facial nerve within the parotid gland was $8.88 \pm 3.55 \mathrm{~mm}$ (4.62 $16.96 \mathrm{~mm})$.

- The distance from the division of the temporofacial trunk into the temporofrontal branch and the orbital branch to the line (d) [crossing through the lateral canthus (A) and the point that root of the helix intersecting with the face] and (d2) [crossing through the lateral canthus and the upper point of the tragus, just above the upper edge of external auditory canal] was $36.06 \pm 7.50 \mathrm{~mm}$ (19.26$45.34 \mathrm{~mm})$ and $21.94 \pm 6.28 \mathrm{~mm}(11.52-$ $37.20 \mathrm{~mm})$.

\section{REFERENCES}

1. Thanh N.V., Vinh L.G.(1991), “ Anatomical characteristics of the frontal branch of the facial nerve'. Morphology journal. 1(2): 8- 10.

2. Gosain A. K., Sewall S.R., Yousif N.J. (1997), "The temporal branch of the facial nerve: how reliably can we predict its path?", Plastic and Reconstructive Surgery, 99(5): 1224-1233.

3. Zani R., Fadul R.Jr., Da Rocha M.A., et al. (2003), "Facial nerve in rhytidoplasty: anatomic study of its trajectory in the overlying skin and the most common sites of injury", Annals of Plastic Surgery, 51(3): 236242.

4. Öksüz C. E., Kalaycioğlu A., Uzun Ö. et al. (2019), "Morphological evaluation of terminal branches of the facial nerve within the parotid gland in fetus cadavers", Cukurova Med J., 44(2): 1

5. Tayfur V., Edizer M., Magden O. (2010), "Anatomic bases of superficial temporal artery and temporal branch of facial nerve", $\mathrm{J}$ Craniofac Surg. 2010 Nov;21(6):1945-7.

6. de Bonnecaze G., Chaput B., Filleron T. et al. (2015), "The frontal branch of the facial nerve: can we define a safety zone?", Surg Radiol Anat. 2015 Jul;37(5):499-506.

7. Farahvash M. R., Yaghoobi A., Farahvash B. et al. (2013), "The extratemporal facial nerve and its branches: analysis of 42 hemifacial dissections in fresh Persian (Iranian) cadavers", Aesthet Surg J., 33(2):201-8. 